\title{
Awareness of Rural People about Prevention of Non-Communicable Diseases
}

\author{
Md. Entekhab-Ul-Alam, 'Md. Nurul Amin, ${ }^{1}$ Md. Jawadul Haque, ${ }_{1}$ Farzana Hasan, ${ }^{2}$ Milon Kumar Haldar, ${ }^{2}$ Nelofar Yasmin, ${ }^{2}$ \\ Shathi Kumar Rawson Kamal Md. Abu Syem Shah Amanath Ullah, ${ }^{2}$ Farhana Yasmin,, Md. Maruful Arefin, ${ }^{2}$ \\ Shitil Ibna Islam, ${ }^{3}$ Shakira Tur Rahman ${ }^{3}$
}

\section{ABSTRACT}

Background \& Objective: Non-communicable diseases, particularly diabetes, hypertension and ischemic heart diseases have created an epidemic situation worldwide. Bangladesh is also in the grip of the menace. The only way to get rid of the menace is prevention of these diseases which demands awareness against the diseases. This study was undertaken to assess the level of knowledge of adult people of Puthia Upazila regarding prevention of the seclected non-communicable diseases (NCDs).

Methods: The study was carried out in the Department of Community Medicine Rajshahi Medical College, Rajshahi over a period of 2 months from April 2018 to May 2018. All adult people (18 years onwards) residing in the rural area of Puthia Upazila were the respondents (study population) in this study. The survey invited the adult individuals to participate in the study. A total of 1001 individuals voluntarily responded to participate in the study. Of them 648(64.7\%) were free from the NCDs and were interviewed to assess their level of knowledge on prevention of selected NCDs. A self-administered questionnaire containing the variables of interest for evaluating knowledge was used.

Result: Two-thirds (68.2\%) of the respondents were 30-50 years old with mean age of the respondents being 44.3(range: $25-90$ ) years. Males outnumbered females by $11: 9$. Over half (54\%) informed that they had little knowledge and $10.7 \%$ were familiar with the NCDs. Around half held the view that diabetes, hypertension, ischemic heart diseases and stroke were $\mathrm{NCD}$ /chronic diseases. Approximately $70 \%$ told that the NCDs were on a rising trend. Regarding causes of chronic diseases, the respondents told excess intake of fat and sedentary life-style $(67.9 \%)$, intake of excess $\mathrm{CHO}(54.2 \%)$, indulgence in smoking $(68.2 \%)$, less intake of vegetables and fruits $(57.4 \%)$, excess or additional salt intake $(50.5 \%)$ and family history of NCD (44.1\%). Regarding prevention of NCDs, around $70 \%$ were in favor of adopting healthy dietary behaviour and avoiding too much fatty food, followed by regular exercise $(71.2 \%)$, avoiding or giving up smoking $(70.8 \%)$ and avoiding or giving up taking extra salt $(57.9 \%)$.

Conclusion: The study concluded that the people of Puthia Upazilla are aware more or less about the selected NCDs (diabetes, hypertension, ischemic heart diseases and stroke). They are also aware that these diseases are increasing. Around two-thirds of the people are aware about the risk factors of these non-communicable diseases and the ways to prevent them.

Key words: Awareness, rural people, prevention and Non-Communicable Diseases (NCDs) etc

\section{Authors' information:}

Dr. Md. Entekhab-UI-Alam, Ex Associate Professor, Department of Community Medicine, Rajshahi Medical College, Rajshahi.

Dr. Md. Nurul Amin, Associate Professor (Research \& Development) \& Executive Editor (Ibrahim Cardiac Medical Journal), Ibrahim Cardiac Hospital \& Research Institute, Shahbag, Dhaka, Bangladesh.

Dr. Md. Jawadul Haque, Professor \& Head, Department Community Medicine, Rajshahi Medical College, Rajshahi, Bangladesh.

${ }_{2}^{2}$ Dr. Farzana Hasan, Medical Officer, Department of Community Medicine, Rajshahi Medical College, Rajshahi.

${ }^{2}$ Dr. Milon Kumar Haldar, Lecturer, Department of Community Medicine, Rajshahi Medical College, Rajshahi.

${ }^{2}$ Dr. Nelofar Yasmin, Lecturer, Department of Community Medicine, Rajshahi Medical College, Rajshahi.

${ }^{2}$ Dr. Shathi Kumar Rawson Kamal, Md. Abu Syem Shah Amanath Ullah, Associate Professor, Institute of Health Technology, Rajshahi Medical College, Rajshahi.

${ }_{2}^{2}$ Dr. Farhana Yasmin, Lecturer, Department of Community Medicine, Rajshahi Medical College, Rajshgahi.

${ }^{2}$ Dr. Md. MarufulArefin, Lecturer, Department of Community Medicine, Rajshahi Medical College, Rajshahi.

${ }^{3}$ Shitil Ibna Islam, Research Officer, Ibrahim Cardiac Hospital \& Research Institute, Shahbag, Dhaka, Bangladesh.

${ }^{3}$ Shakira Tur Rahman, Research Assistant, Saquib Consultancy Firm, Dhaka, Bangladesh.

Correspondence: Dr.Md. Entekhab-Ul-Alam,Phone:+880 1713228388.E-mail:ealam4@gmail.com 


\section{INTRODUCTION:}

Non-communicable diseases (NCDs) are the major public health challenges in current health scenario worldwide. ${ }^{1}$ NCDs are the leading global causes of death, causing more deaths than all other causes combined. Globally almost 41 million deaths are caused by NCDs each year, which is equivalent to $71 \%$ of all deaths. Almost 15 million people die from NCDs annually between the ages of 30-69 years; over $85 \%$ of these "premature" deaths occur in lowand middle-income countries. ${ }^{2}$ More than 463 million adults are living with diabetes, and this figure is projected to be 700 million by the year $2045 .^{3}$ Hypertension is the commonest cardiovascular disorder, posing a major public health challenge to populations in which socioeconomic and epidemiological transition is going on. WHO reported an estimated ${ }^{1} .13$ billion people have hypertension worldwide, most (two-thirds) living in low-and middle-income countries. ${ }^{4}$ Currently NCDs like diabetes, cardiovascular diseases, cancer \& chronic respiratory disease are major public health concern of developing countries. Almost $60 \%$ deaths, in Bangladesh, are due to NCDs ( $17 \%$ cardiovascular and $11 \%$ chronic respiratory diseases, $10 \%$ cancers, $9 \%$ injuries, $3 \%$ diabetes and $10 \%$ other NCDs). ${ }^{5}$ In developing countries like Bangladesh, the burden of NCDs is even more challenging. ${ }^{1}$

Although NCDs are emerging modern epidemic worldwide, awareness against it is very poor. So are treatment and control measures taken. Risk factors like tobacco use, physical inactivity, unhealthy diet, alcohol consumption, raised blood pressure (BP), and excess adiposity are mostly responsible for NCDs. ${ }^{6}$ Despite lifestyle and behavioral modifications being recognized as a cost-effective strategy for controlling NCDs in the community, there are some barriers that prevent people from adopting a healthy life-style, which can be overcome by constant encouragement and appropriate education to the people. ${ }^{7}$ In a qualitative study $^{8}$ at Upazila (Subdistrict level) Health Complex, participants described that NCD corners have contributed substantially to increase awareness against NCDs, deliver NCD care \& provide referral services. However, they identified numerous challenges including lack of specific guidelines and standard operating procedures, lack of trained human resources, inadequate laboratory facilities, logistics and medications and poor recording and reporting systems.

With recognition of the challenges of implementing an NCD control program in a resource-poor country like Bangladesh, a study to assess the social, cultural, and behavioral factors could be an implementation research priority. The findings generated from the study may expedite the ongoing NCD control program of Govt. of Bangladesh. That purpose, the present community-based study was undertaken to assess the level of awareness of rural people of Bangladesh toward prevention and early detection of common NCDs. The information and evidence gathered are expected to identify some of the social barriers to successful implementation of NCD control program in rural areas of Bangladesh.

\section{METHODS:}

This descriptive cross-sectional study was carried out in the Department of Community Medicine Rajshahi Medical College, Rajshahi over a period of 2 months from April 2018 to May 2018. The survey invited adult individuals (18 or $>18$ years old) to participate in the study. A total of 1001 individuals voluntarily responded to participate in the study. Of them $107(10.7 \%)$ were diabetic, $246(24.6 \%)$ were hypertensive or had ischemic heart diseases. The rest $648(64.7 \%)$ were free from these conditions and were selected for interview. A self-administered questionnaire containing the variables of interest for evaluating knowledge on prevention of chronic or non-communicable diseases (the diseases that cannot be transmitted directly from one person to another) was used. Keeping compliance with Helsinki Declaration for Medical Research Involving Human Subjects 1964, last amended in 2013, all the subjects selected for the study were informed prior to data collection and verbal consent was obtained from them. The sociodemographic characteristics of the respondents studied were age, sex, marital status, educational level and family income, while the perception about the disease included variables 
like general knowledge about NCDs, knowledge on specific NCDs, causes of NCDs and ways to prevent them. Weight and height data of all respondents were recorded to calculate BMI and to categorize the respondents as underweight (BMI $<18.5 \mathrm{~kg} / \mathrm{m}^{2}$ ), normal BMI (BMI 18.5-24.9 kg/m²), overweight (BMI 25.0-29.9 kg/m²), obese (BMI $30-39.9 \mathrm{~kg} / \mathrm{m}^{2}$ ) and morbidly obese (BMI $\geq 40 \mathrm{~kg} / \mathrm{m}^{2}$ ). Collected data were processed and analyzed using software SPSS (Statistical Package for Social Sciences), version 17.0. Statistical analyses were done using descriptive statistics. The data presented on categorical scale were expressed as frequency and corresponding percentage, while the data presented on continuous scale were presented as mean, median and standard deviation from the mean.

\section{RESULTS:}

Age distribution of the respondents shows that nearly half $(48.3 \%)$ of the respondents were in their $3^{\text {rd }}$ decade of life followed by $19.9 \%$ in $4^{\text {th }}, 15.4 \%$ in $5^{\text {th }}$ and $11.3 \%$ in $2^{\text {nd }}$ decade of life. Only $5 \%$ respondents were elderly (> 60 years old). The mean age of the respondents was 44.3 years (range: 25-90 years) (Table I). Out of 648 respondents, $366(56 \%)$ were females and the rest $282(44 \%)$ were males with female to male ratio being roughly $11: 9$ (Fig.1). Over $50 \%$ of the respondents were housewife. Farming (17.1\%) and business (14.2\%) were $3^{\text {rd }} \& 4^{\text {th }}$ occupations respectively. The median monthly income of the respondents was Taka 10000 with lowest and highest incomes being Taka 1000 and 10000 respectively. Majority $(91.2 \%)$ of the respondents was married. Primary level educated formed the main bulk (41.5\%) followed by SSC $(30.6 \%)$, HSC $(5.9 \%)$, graduate \& masters $(4.2 \%)$. A sizable portion of the respondents $(30.6 \%)$ was illiterate as well (Table II). Over $55 \%$ of the respondents were of normal BMI, 30.9\% overweight, $8.6 \%$ obese, $4.8 \%$. underweight. Morbidly obese was rare (0.6\%) (Fig. 2).

Asked about how much they knew about NCD/chronic diseases, over one-third (35.3\%) informed that they were unaware of these diseases or just heard the term, 54\% informed that they had little knowledge and $10.7 \%$ were familiar with the diseases (Table III). Around half (50\%) of the respondents held the view that diabetes, hypertension, ischemic heart diseases or stroke were NCDs. The rest informed that they did not know (Table IV). Asked about whether chronic diseases were increasing, approximately $70 \%$ nodded that they think so. Of the rest, $4.5 \%$ opined that they were not increasing and $25.7 \%$ told that they knew nothing about it (Table $\mathrm{V}$ ). In response to another question, what causes chronic diseases, the respondents told intake of excess carbohydrate $(54.2 \%)$, excess intake of fat and sedentary life-style $(67.9 \%)$, smoking habit $(68.2 \%)$, less intake of vegetables and fruits (57.4\%), excess or additional salt intake (50.5\%) and family history of NCDs (44.1\%) (Table VI). Asked about how chronic disease could be prevented, the respondents emphasized on adopting healthy dietary behavior $(69.6 \%)$, avoiding too much fatty food $(72.5 \%)$, followed by regular exercise (71.2\%), avoiding or giving up smoking (70.8\%) and taking extra salt (57.9\%) (Table VII).

\begin{tabular}{|lcc|}
\hline \multicolumn{3}{|c|}{ Table I. Distribution of respondents by their age $(\mathbf{n}=\mathbf{6 4 8})$} \\
\hline Age* (years) & Frequency & Percentage \\
$<30$ & 33 & 11.3 \\
$30-40$ & 313 & 48.3 \\
$40-50$ & 129 & 19.9 \\
$50-60$ & 100 & 15.4 \\
$>60$ & 73 & 5.1
\end{tabular}

${ }^{*}$ Mean age $=(44.3 \pm 12.3)$ years; range $=(25-90)$ years.

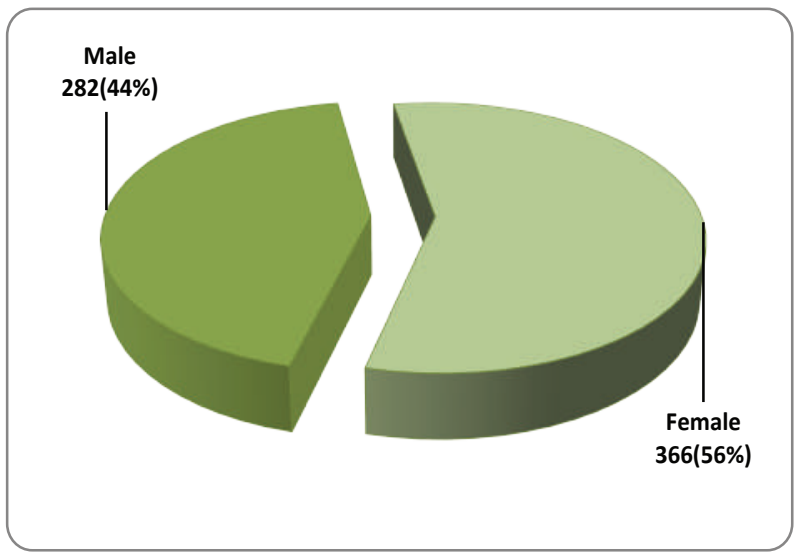

Fig.1: Sex distribution of the respondents $(n=648)$ 


\begin{tabular}{|c|c|c|c|}
\hline $\begin{array}{l}\text { Other } \\
\text { demographics }\end{array}$ & Frequency & Percentage & Mean \pm SD \\
\hline \multicolumn{4}{|l|}{ Occupation } \\
\hline Service & 56 & 8.6 & --- \\
\hline Housewife & 332 & 51.3 & --- \\
\hline Farmer & 111 & 17.1 & --- \\
\hline Business & 92 & 14.2 & --- \\
\hline Others & 57 & 8.8 & --- \\
\hline Median income (Taka) & --- & --- & $\begin{array}{r}10000 \pm 8163 \\
(1000-100000)\end{array}$ \\
\hline \multicolumn{4}{|l|}{ Marital status } \\
\hline Married & 591 & 91.2 & --- \\
\hline Unmarried & 29 & 4.5 & --- \\
\hline Divorced & 4 & 0.6 & --- \\
\hline Widow & 20 & 3.1 & --- \\
\hline Widower & 4 & 0.6 & --- \\
\hline \multicolumn{4}{|l|}{ Education } \\
\hline Illiterate & 196 & 30.6 & --- \\
\hline Primary & 269 & 41.5 & --- \\
\hline SSC & 101 & 15.6 & --- \\
\hline $\mathrm{HSC}$ & 38 & 5.9 & --- \\
\hline Graduate \& Masters & 27 & 4.2 & --- \\
\hline Non-formal & 14 & 2.2 & --- \\
\hline
\end{tabular}

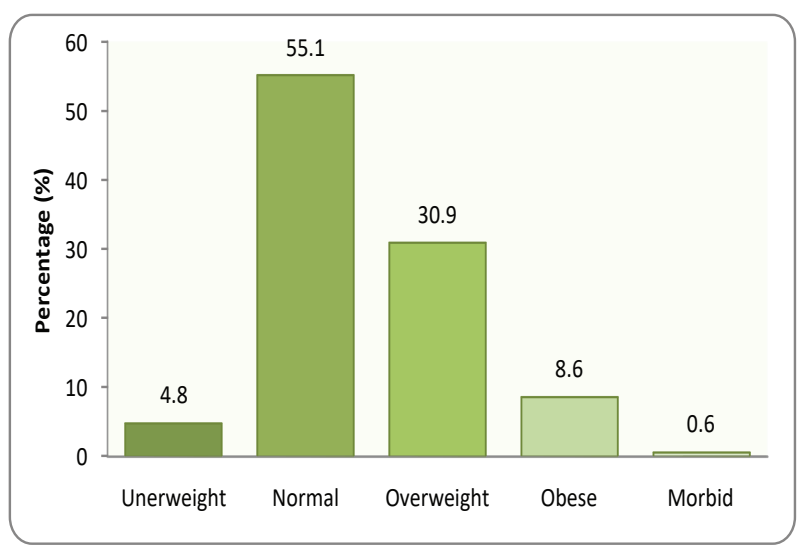

Fig. 2: Distribution of respondents by their BMI $(n=648)$

\begin{tabular}{|c|c|c|}
\hline General knowledge about NCD & Frequency & Percentage \\
\hline Nothing or only heard the term & 229 & 35.3 \\
\hline Little knowledge & 350 & 54.0 \\
\hline Familiar & 69 & 10.7 \\
\hline
\end{tabular}

\begin{tabular}{|c|c|c|}
\hline Knowledge on specific NCDs & Frequency & Percentage \\
\hline \multicolumn{3}{|l|}{ DM } \\
\hline Yes & 360 & 55.6 \\
\hline No & 69 & 10.7 \\
\hline Don't know & 219 & 33.7 \\
\hline \multicolumn{3}{|l|}{ HTN } \\
\hline Yes & 365 & 56.3 \\
\hline No & 63 & 9.7 \\
\hline Don't know & 220 & 34.0 \\
\hline \multicolumn{3}{|l|}{ IHD } \\
\hline Yes & 319 & 49.2 \\
\hline No & 70 & 10.8 \\
\hline Don't know & 259 & 40.0 \\
\hline \multicolumn{3}{|l|}{ Stroke } \\
\hline Yes & 273 & 42.1 \\
\hline No & 68 & 10.5 \\
\hline Don't know & 307 & 47.4 \\
\hline
\end{tabular}

Table V. Respondents' knowledge on trend of chronic diseases $(n=648)$

Knowledge on trend of chronic diseases Frequency Percentage $\begin{array}{lll}\text { Increasing } & 452 & 69.8\end{array}$

Not increasing $\quad 29 \quad 4.5$

$\begin{array}{lll}\text { Don't know } & 167 & 25.7\end{array}$

Table VI. Respondents' knowledge on causes of chronic diseases $(n=648)$

$\begin{array}{lcc}\text { Causes of chronic disease } & \text { Frequency } & \text { Percentage } \\ \text { Excess intake of CHO } & & \\ \text { Yes } & 351 & 54.2 \\ \text { No } & 74 & 11.4 \\ \text { Don't know } & 223 & 34.4 \\ \text { Excess intake of fat } & & \\ \text { Yes } & 440 & 67.9 \\ \text { No } & 58 & 9.0 \\ \text { Don't know } & 150 & 23.1 \\ \text { Sedentary Life-style } & & \\ \text { Yes } & 437 & 67.4 \\ \text { No } & 58 & 9.0 \\ \text { Don't know } & 153 & 23.6 \\ \text { Smoking } & & \\ \text { Yes } & 442 & 68.2 \\ \text { No } & 63 & 9.7 \\ \text { Don't know } & 143 & 22.1 \\ \text { Less intake of vegetables \& fruits } & & \\ \text { Yes } & 372 & 57.4 \\ \text { No } & 67 & 10.3 \\ \quad \text { Don't know } & 209 & 32.3 \\ \text { Excess intake of salt } & & \\ \text { Yes } & 327 & 50.5 \\ \text { No } & 76 & 11.7 \\ \text { Don't know } & 245 & 37.8 \\ \text { F/H of NCD } & & \\ \text { Yes } & 286 & 44.1 \\ \text { No } & 103 & 15.9 \\ \text { Don't know } & 259 & 40.0 \\ \quad & & \\ & & \end{array}$




\begin{tabular}{lcc|}
$\begin{array}{l}\text { Table VII. Respondents' knowledge on ways to preventing } \\
\text { of chronic diseases ( } \mathbf{n}=\mathbf{6 4 8} \text { ) }\end{array}$ & \\
\hline $\begin{array}{l}\text { Ways of preventing } \\
\text { chronic diseases }\end{array}$ & Frequency & Percentage \\
\hline $\begin{array}{l}\text { Healthy dietary behaviour } \\
\text { Yes }\end{array}$ & 451 & \\
No & 21 & 69.6 \\
Don't know & 176 & 3.2 \\
Avoiding too much fatty food & & 27.2 \\
Yes & 470 & \\
No & 20 & 72.5 \\
Don't know & 158 & 3.1 \\
Taking regular exercise & & 24.4 \\
Yes & 461 & \\
No & 19 & 71.2 \\
Don't know & 168 & 2.9 \\
Avoiding or giving up smoking & & 25.9 \\
Yes & 459 & \\
No & 14 & 70.8 \\
Don't know & 175 & 2.2 \\
Avoiding or giving up extra salt & & 27.0 \\
Yes & 375 & 57.9 \\
No & 22 & 3.4 \\
Don't know & 251 & 38.7 \\
\hline & & \\
\hline
\end{tabular}

\section{DISCUSSION:}

In the present study almost half of the respondents wasearly-middle aged (30-40 years old) with mean age being $44.3 \pm 12.3$ (range: $25-90$ ) years which is almost similar with the findings of Nujhat et $\mathrm{al}^{9}$ and Ojo et $\mathrm{al}^{10}$ who showed mean age of their respondents to be $41.9 \pm 15.7$ and $43.6 \pm 7.7$ years respectively. Females outnumbered males by 11:9. Studies conducted in Bangladesh, Uganda and India also found female respondents to be higher than male..$^{9-11}$

In the present study more than half $(51.3 \%)$ of the respondents was housewife and over $40 \%$ were primary level educated, whereas a similar study in Uganda showed farming to be the main occupation and secondary level educated to form the majority. ${ }^{10}$ The present study revealed that $40 \%$ of the respondents were overweight or obese. Consistent with this finding, Nujhat and associates ${ }^{9}$ in a recent study showed that $43 \%$ of the rural people of Bangladesh selected for their interview were overweight and obese in terms of BMI. In our study one-third (35.3\%) was completely unaware of NCDs or just heard the term, $54 \%$ had little knowledge and the rest were more or less knowledgeable about NCDs. An Indian study found that more than $80 \%$ of the study participants had heard of the words diabetes, hypertension and coronary heart disease as NCDs. ${ }^{11}$ In Ojo's ${ }^{10}$ study majority $(94.1 \%)$ of the respondents was aware that NCDs could not spread between people through contact. Most of the respondents in the study of Srivastava et $\mathrm{al}^{11}$ considered lifestyle to play a role in the development of NCDs and less than $40 \%$ of the respondents were aware of the role of nutrition in the development of NCDs. Knowledge and practice for NCD prevention were found to be poor. Nujhat ${ }^{9}$ showed that $46.8 \%$ and $64.4 \%$ were not aware of risk factors of developing hypertension and diabetes respectively.

In response to a question whether diabetes, hypertension, ischemic heart diseases or stroke were $\mathrm{NCD} /$ chronic diseases, around half was of the opinion that they were NCDs, which is consistent with the findings of Ojo et al ${ }^{10}$ who reported that $63.2 \%$ of the respondents were aware about diabetes, $61.8 \%$ about heart diseases, $52.9 \%$ about stroke, $70.6 \%$ about high blood pressure. Nearly $90 \%$ of the respondents held the view that cardiovascular diseases are becoming more common in Uganda.

A study conducted in Karnataka, India about NCDs awareness among rural secondary schools adolescents demonstrated that approximately 63\% of the respondents had no idea about prevention of NCDs. Over one-third (37\%) students felt NCDs are preventable and only $0.3 \%$ had good level of knowledge regarding the lifestyle risk factors. Knowledge regarding communicability of these lifestyle-related diseases was good among students. About two-thirds (65.6\%) of the students knew that they were non-communicable and one-third (34.4\%) had misconception about the NCDs. Daily consumption of fast food was low (6.8\%). Majority $(93.2 \%)$ of the students was used to playing outdoor games daily like kabaddi, cricket, volleyball, badminton, kho-kho etc. considered as healthy behavior for their health. As many as $68.5 \%$ of the students were accustomed to consuming fruits and vegetables daily. ${ }^{12}$ 
In response to what causes of NCDs, the respondents mentioned intake of carbohydrate-rich diet $(55 \%)$, intake of too much fat and adopting sedentary life-style $(68 \%)$, indulgence in smoking $(68.2 \%)$, less intake of vegetables and fruits $(57.4 \%)$, and used to taking additional salt $(50.5 \%)$ along with family history of NCDs (44.1\%). Regarding chronic disease prevention, majority was in favor of adopting healthy dietary behavior, avoiding too much fatty food, regular exercise, avoiding or giving up smoking and having extra salt.

\section{CONCLUSION:}

This study concluded that the rural people of Puthia Upazilla are more or less aware about the selected non-communicable diseases (diabetes, hypertension, ischemic heart diseases and stroke). They are also aware that these diseases are increasing. Around two-thirds of the people are aware about the causes/risk factors of these NCDs and the ways to prevent them. Although their practice status to prevent these NCDs is not investigated, it is recommended that health education should be geared up to encourage them turn their knowledge into practice.

\section{REFERENCES:}

1. Mane KS, Maganalli A, Nawaz AS. A comparative study on awareness about non-communicable diseases and their risk factors among government and private high school students of Davangere city. International Journal of Medical Science and Public Health 2016;5(10):2026-2019.

2. WHO, 2020 Noncommunicable diseases,Availablea at: https://www.who.int/news-room/fact-sheets/detail/nonc ommunicable-diseases.

3. The International Diabetes Federation (IDF), 2019 About Diabetes. Diabetes facts \& figures. Availablea at: https: //www.idf.org/aboutdiabetes/what-is-diabetes/facts-figur es.html.

4. WHO, Hypertension 2019Availablea at: https://www.who. int/news-room/fact-sheets/detail/hypertension \# : : text= An\%20estimated\%201.13\%20billion\%20people,\%2D\%2 0and\%20middle\%2Dincome\%20countries.

5. Noncommunicable Diseases Country Profile 2014. World Health Organization, Geneva, Switzerland, 2014. Availablea at: http://www.who.int/nmh/publications/ncdprofiles-2014/ en/ [last accessed on May 12, 2016.
6. Epping-Jordan JE, Galea G, Tukuitonga C, Beaglehole R. Preventing chronic diseases: Taking stepwise action. Lancet 2005;366:1667-71.

7. Chobanian AV, Bakris GL, Black HR, Cushman WC, Green LA, Lzzo JL Jr, Joint National Committee on Prevention, Detection, Evaluation, and Treatment of High Blood Pressure. National Heart, Lung, and Blood Institute; National High Blood Pressure Education Program Coordinating Committee. Seventh Report of the Joint National Committee on Prevention, Detection, Evaluation and Treatmentof High Blood Pressure. Hypertension 2003;42:1206-52. Available AT: http:/www.theheart.org/ article/ Accessed on 05.06.2010.

8. Rawal LB, Kanda K, Biswas $T$ et al. Noncommunicable disease (NCD) corners in public sector health facilities in Bangladesh: a qualitative study assessing challenges and opportunities for improving NCD services at the primary healthcare level. BMJ Open 2019;9:e029562. doi:10. 1136/bmjopen-2019-029562

9. Nujhat S, Alam W, Parajuli A, Mohsen WAM, Banyira L, Gupta RD, Mridha MK 2020. Prevalence of risk factors for non-communicable diseases in a rural population of Bangladesh: a cross-sectional study. The Lancet Global Health 8:S21. doi:10.1016/s2214-109x(20)30162-5.

10. Ojo $T$, Hawley NL, Desai MM, Akiteng AR, Guwatudde $D$, Schwartz JI. Exploring knowledge and attitudes toward non-communicable diseases among village health teams in Eastern Uganda: a crosssectional study. BMC Public Health 2017;17:947, DOI 10.1186/s12889-017-4954-8.

11. Srivastava R, Gupta A, Chinnakali P, Aslesh OP, Yadav K, Gupta V, Goswami A, Nongkynrih B. Awareness about Non Communicable Diseases and Role of Nutrition among an Urban Resettlement Population of Delhi. Ind J Nutr Dietet 2014;51:429-438.

12. Ade A, Chethana KV, Mane A ,Hiremath SG. Noncommunicable diseases: Awareness of risk factors and lifestyle among rural adolescents. Anju Ade et. al Int J Biol Med Res 2014;5(1): 3769-3771. 